\title{
Study on the Behavior of Gongan Changjiang Combined Highway and Railway Bridge under Wind
}

\author{
Shi-Xiong ZHENG ${ }^{1, a^{*}}$, Lun-Xiong $\mathrm{YI}^{2, \mathrm{~b}}$, Xiang-Xu ZHANG ${ }^{1, \mathrm{c}}$ \\ ${ }^{1}$ School of Civil Engineering, Southwest Jiaotong University, Chengdu,PRC,610031 \\ ${ }^{2}$ China Zhongtie Major Bridge Reconnaissance \& Design Intitute Co., Ltd., Wuhan, PRC,430050 \\ azhengsx@swjtu.edu.cn, byilx@brdi.com.cn, ${ }^{\circ} 568160681 @ q q . c o m$ \\ ${ }^{*}$ Corresponding author
}

Keywords: Cable-stayed Bridge, Truss Beam Bridge, Wind-tunnel Test, Flutter, Vortex-induced Vibration, Buffeting.

\begin{abstract}
Gongan Changjiang combined highway and railway bridge is a steel truss beam cable-stayed bridge, which main span is $518 \mathrm{~m}$, In this paper, the behavior of the bridge under wind is systematically studied by analysis or by wind-tunnel model test. The wind characters at bridge location are analyzed. The vibration characters of the bridge are calculated. The static aerodynamic coefficients of the main girder were measured, the flutter stability and the vortex-induced vibration performance were studied by the sectional model wind tunnel test. The aero-elastic model wind tunnel test for the completion state and the construction stage of the bridge are carried out. It is shown. the Aerodynamic stability of the main girder is satisfied. The amplitude of vortex-induced vibration and the buffeting responses are all meet the need of the national code.
\end{abstract}

\section{Introduction}

Gongan Changjiang combined highway and railway bridge is a steel truss girder cable-stayed bridge. Its arrangement of spans is $(98+182+518+182+98) \mathrm{m}$. The H-typed bridge towers are made of reinforced concretes. The steel truss girder is an $\mathrm{N}$-shaped girder. The height of the truss is $13.0 \mathrm{~m}$, the inter node length is $14.0 \mathrm{~m}$. The section of steel truss girder is inverted trapezoidal. The bridge floor is arranged in two layers. The upper bridge floor is 4-lane road, with a width of $26.0 \mathrm{~m}$, which is composed of the roof plate of upper chord and the steel bridge deck on the road. The lower bridge floor is a double-track railway, and spacing between the two tracks is $4.2 \mathrm{~m}$. The deck is composed of orthotropic steel plate and truss. The anchorage of stay cables are arranged at the both sides of the upper bridge floor, the distances between two anchorage is $26.7 \mathrm{~m}$.

4 longitudinal dampers are arranged at the junction of bridge tower and truss girder. The damping value for each damper is $\mathrm{Cd}=3000 \mathrm{KN} /(\mathrm{s} / \mathrm{m}) \alpha$, and the damping exponent $\alpha$ is 0.4 .

The terrain roughness of the bridge site is B class. For completed bridge state, the design standard wind speed at level of the bridge girder is $34.4 \mathrm{~m} / \mathrm{s}$, accordingly, the flutter checking wind speed is $52.8 \mathrm{~m} / \mathrm{s}$. For construction stage and return period is 10 year[1][2], the design standard wind speed at level of the bridge girder is $28.9 \mathrm{~m} / \mathrm{s}$, accordingly, the flutter checking wind speed is $44.4 \mathrm{~m} / \mathrm{s}$.

The dynamic properties of Gongan Changjiang combined highway and railway bridge are calculated with ANSYS. For completed bridge state, the first vertical bending frequency is $0.333 \mathrm{~Hz}$, and the first torsional frequency is $0.710 \mathrm{~Hz}$. For the largest double-cantilever state, the first vertical bending frequency is $0.232 \mathrm{~Hz}$, and the first torsional frequency is $0.918 \mathrm{~Hz}$.

The girder's section of Gongan Changjiang combined highway and railway bridge is special. It has large span, high design wind speed, and low structural fundamental frequency. In order to ensure wind resistance safety of the bridge at the completion state and the construction stage, in this paper, the wind tunnel test and analytical was performance. 


\section{Static Aerodynamic Parameters Measurements for the Truss Girder by Wind Tunnel Test}

The static aerodynamic coefficients of the girder are the key parameters for calculating the wind-induced response of the bridge. The girder's and the train's aerostatic coefficients are also used in studied the vehicle bridge coupling vibration when considering the wind load.

The static aerodynamic coefficients can be obtained through the sectional model wind tunnel test . The sectional model test was performed in the second work section of the XNJD-1 wind tunnel of the Southwest Jiaotong University. The scale ratio of the model is $1: 60$, and the length of $2.1 \mathrm{~m}$. These coefficients were measured by a force balance in a smooth flow, and the yaw angle that varied from $-12^{\circ}$ to $+12^{\circ}$ in steps of $1^{\circ}$. The incoming wind velocities in test are $10 \mathrm{~m} / \mathrm{s}, 20 \mathrm{~m} / \mathrm{s}$ and $30 \mathrm{~m} / \mathrm{s}$. Figure 1 shows the average static aerodynamic coefficients of the bridge in the completion state or in the construction stage.

The wind tunnel test was also carried out when the train was on the bridge and when the wind attack angle is $0^{\circ}$. The static aerodynamic coefficients of the train or of the bridge were measured. Tab.1 show these coefficients. Two types of train were considered, which is $25 \mathrm{~T}$ passenger train and $\mathrm{C} 80$ freight train.

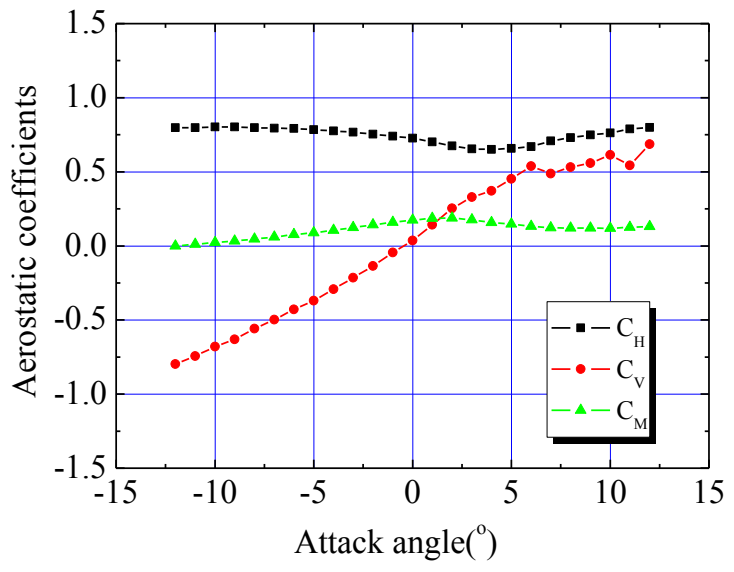

(a) The Construction State

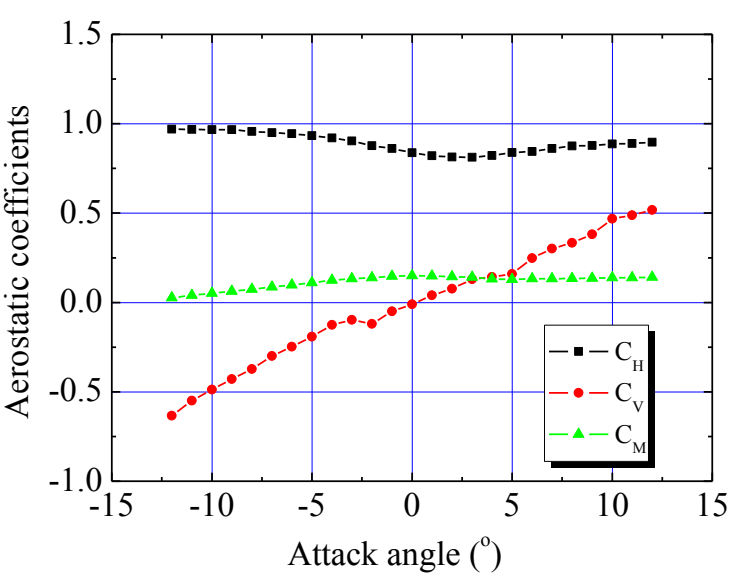

(b) The Finished State

Fig.1 The Static Aerostatic Coefficients of the Truss Girder Versus Angle of Attack

Tab.1 The Static Aerostatic Coefficients of the Bridge and the Train

\begin{tabular}{c|c|c|c|c|c|c|c}
\hline \multirow{2}{*}{ Case } & \multirow{2}{*}{ Structure } & \multicolumn{6}{|c}{ Static aerostatic coefficients } \\
\cline { 3 - 8 } & & \multicolumn{2}{|c|}{$25 \mathrm{~T}$ passenger train } & \multicolumn{3}{c}{$\mathrm{C} 80$ freight train } \\
\cline { 3 - 8 } & $\mathrm{C}_{\mathrm{H}}$ & $\mathrm{C}_{\mathrm{V}}$ & $\mathrm{C}_{\mathrm{M}}$ & $\mathrm{C}_{\mathrm{H}}$ & $\mathrm{C}_{\mathrm{V}}$ & $\mathrm{C}_{\mathrm{M}}$ \\
\hline \multirow{2}{*}{$\begin{array}{c}\text { A train on } \\
\text { upwind side }\end{array}$} & truss girder & 0.963 & 0.376 & 0.133 & 0.964 & 0.378 & 0.134 \\
\cline { 2 - 8 } $\begin{array}{c}\text { A train on } \\
\text { leeward side }\end{array}$ & Train & 0.463 & 0.749 & 0.458 & 0.525 & 0.761 & 0.417 \\
\cline { 2 - 8 } & truss girder & 0.920 & 0.312 & 0.127 & 0.921 & 0.311 & 0.127 \\
\hline \multirow{3}{*}{$\begin{array}{c}\text { Two trains on } \\
\text { track }\end{array}$} & truss girder & 0.740 & 0.821 & 0.967 & 0.793 & 0.829 & 0.954 \\
\cline { 2 - 8 } & $\begin{array}{c}\text { Train on the } \\
\text { upwind }\end{array}$ & 0.412 & 0.645 & 0.458 & 0.469 & 0.639 & 0.453 \\
\cline { 2 - 8 } & $\begin{array}{c}\text { Train on the } \\
\text { leeward }\end{array}$ & 0.087 & 0.182 & 0.212 & 0.088 & 0.183 & 0.211 \\
\hline
\end{tabular}

It is showed that when the wind attack angle is $0^{\circ}$, the drag coefficient of the girder at completion state is 0.838 , and is 0.726 in the stage of construction. Either in the completion state or the construction stage, the slopes of lift coefficient curve and moment coefficient curve are all positive values in the range of wind attack angles $\left(-12^{\circ} \leq \alpha \leq+5^{\circ}\right)$. That is to say. the conditions of aerodynamic stabilization are meet for the section of the girder. 
From Table 1, for the truss girder, existence of the train likely plays the roles of increasing the lift coefficient and moment coefficient or reducing the resistance coefficient. Because the truss girder's section has special form, when the train runs on the downwind line, the drag coefficient is larger than that when the train runs on the upwind line.

\section{The Sectional Model Wind Tunnel Test for the Dynamic Performance of the Girder}

The dynamic performance of the girder includes flutter stability and vortex-induced vibration performance, and which can be studied through the sectional model wind tunnel test or the aero-elastic model wind-tunnel test for the whole bridge $[3,4,5]$.

Sectional model wind tunnel test is economic and rapid. The sectional model was supported by 8 springs. Measuring the frequencies of the system. On the basis of the similarity law, the scale ratio of model and the frequency ratio of model and real bridge, determining the wind speed ratio of wind tunnel test. 3 attack angles for either completion state or construction stage were considered.

The dynamic sectional model test shall be conducted under the condition of uniform flow, and the attack angles are $\alpha=0^{\circ},+3{ }^{\circ}$, and $-3^{\circ}$. The Table 2 provides the wind tunnel test results of flutter critical wind speed, from this table, we can see that the main bridge flutter critical wind speed of Gongan Changjiang combined highway and railway bridge is greater than the flutter checking wind speed in corresponding state.

The girder's vortex-induced vibration performance can also be studied through the wind tunnel test of dynamic sectional model. Tests were also performed under three attack angles of $\alpha=0^{\circ},-3^{\circ}$, and $+3^{\circ}$. The incoming wind are uniform flows too.

It is showed. Under small damping $(0.25 \%)$ and at the completion bridge state, for wind attack angle was $-3^{\circ}$, no vertical vortex induced vibration occurred. For wind attack angle was $0^{\circ}$, the vertical vortex induced vibration which maximum amplitude was $22 \mathrm{~mm}$ occurred when wind speed was about $15 \mathrm{~m} / \mathrm{s} \sim 17 \mathrm{~m} / \mathrm{s}$. For wind attack angle was $+3^{\circ}$ and the wind speed was $13 \mathrm{~m} / \mathrm{s} \sim 17 \mathrm{~m} / \mathrm{s}$, and the maximum amplitude of vertical vortex induced vibration is $77 \mathrm{~mm}$. For 3 wind attack angles which were $\alpha=-3, \alpha=0^{\circ}$ and $\alpha=+3^{\circ}$, there are no torsional vortex induced vibration.

Tab. 2 The Results of the Direct Method for the Flutter Test

\begin{tabular}{c|c|c|c|c|c}
\hline \multicolumn{2}{c|}{ Case } & $\begin{array}{c}\text { model test Vcr } \\
(\mathrm{m} / \mathrm{s})\end{array}$ & wind speed ratio & $\begin{array}{c}\text { real bridge Vcr } \\
(\mathrm{m} / \mathrm{s})\end{array}$ & flutter modality \\
\hline \multirow{2}{*}{$\begin{array}{c}\text { The } \\
\text { completion } \\
\text { state }\end{array}$} & $+3^{\circ}$ & 15.1 & 6.310 & 95.2 & torsion \\
\cline { 2 - 6 } & $0^{\circ}$ & 17.7 & 6.310 & 111.6 & torsion \\
\hline \multirow{2}{*}{$\begin{array}{c}\text { The } \\
\text { longest } \\
\text { double- } \\
\text { cantilever }\end{array}$} & $-3^{\circ}$ & $>19.4$ & 6.310 & $>122$ & - \\
\cline { 2 - 6 } & $0^{\circ}$ & 21.7 & 4.579 & 99.3 & torsion \\
\hline At the con & $>24.0$ & 4.579 & $>109.8$ & - \\
\hline
\end{tabular}

At the construction phase of the largest double- cantilever, when the wind attack angles were $-3^{\circ}$ or $0^{\circ}$, no vertical vortex vibration occurred. when the wind attack angles was $+3^{\circ}$ and the wind speed was about $10 \mathrm{~m} / \mathrm{s} \sim 13 \mathrm{~m} / \mathrm{s}$, the maximum amplitude of vertical vortex induced was $52 \mathrm{~mm}$. when the wind attack angle was $-3^{\circ}$. no torsional vortex vibration occurred. when the wind attack angle was $0^{\circ}$, the maximum amplitude of torsional vortex vibration was $0.065^{\circ}$ under the wind speed of $25 \mathrm{~m} / \mathrm{s} \sim 30 \mathrm{~m} / \mathrm{s}$. When the wind attack angle was $+3^{\circ}$, the torsional vortex vibration occurred under the wind speed of $25 \mathrm{~m} / \mathrm{s} \sim 32 \mathrm{~m} / \mathrm{s}$, and the maximum amplitude was $0.14^{\circ}$.

The limit value of vortex-induced vibration amplitude shall be based on clause 7.2.6 in specification [1]. At the completion bridge state, the allowable values for vertical vortex vibration amplitude and torsional vortex vibration amplitude respectively are $0.12 \mathrm{~m}$ and $0.247 \mathrm{o}$, and at 
construction phase of the longest double-cantilever, the allowable values for vertical vortex vibration amplitude and torsional vortex vibration amplitude respectively are $0.172 \mathrm{~m}$ and 0.1910 . The conclusion can be get. Whether at the completion state or at the construction stage, under 3 wind attack angles of $\alpha=-3, \alpha=0^{\circ}$ and $\alpha=+3^{\circ}$, both of vertical vortex vibration amplitude and torsional vortex vibration amplitude are all less than the allowable values specified in the specification, meeting requirements of relevant specification.

\section{The Aero-elastic Model Wind Tunnel Test}

Wind tunnel test of the aero-elastic model were carried out for the completion bridge state, the longest double-cantilever stage and longest single-cantilever phase. In general, the basic frequency of the cable-stayed bridge in the state of the largest cantilever is often lower than that in the the completion state. So, the wind-induced buffeting response at the constructon stage may be more disadvantaged for the wind resistance design. The aero-elastic model wind tunnel tests in various states were conducted in XNJD-3, which is the largest bounding layer wind tunnel in the world. It locatied in Southwest Jiaotong University.

The test flow field is uniform flow field or turbulent flow field[6,7]. The uniform flow field test is mainly used for researching vortex vibration response or flutter performance. While the turbulent flow field wind tunnel test is mainly used for investigating its buffeting response performance. For the turbulent flow field wind tunnel test, in addition to that the aero-elastic model must meet the similar low, the wind characteristics of turbulent flow field must also meet simulation low. That is to say, the wind characteristics in the wind tunnel are same as the characteristics of real atmospheric boundary layer flow field at the bridge site. The wind characteristics are mean wind speed profile, the profile of turbulent flow strength and turbulent flow wind spectrum etc.

The similar low of model are the outline dimension similarity, structural dynamic characteristics similarity, and similar damping performance. In design of the aero elastic model, the consistency conditions of elastic parameters and inertial parameters must be strictly met, to ensure that structural dynamic characteristics of the model are similar to the prototype, as well as displacement, internal force and other mechanics parameters are similar with the prototype, the geometric model scale of the model is $1: 80$, and the wind speed ratio is $C_{U}=1 / 8.94$, according to the similar conditions, we can get the frequency ratio $C_{f}=8.94 / 1$, and whole length of the model is $13.5 \mathrm{~m}$.

The lateral displacement, vertical displacements and torsion angles at typical sections were measured with laser displacement meter for each coming wind speed. The incoming wind speed was from $1 \mathrm{~m} / \mathrm{s}$ to $7 \mathrm{~m} / \mathrm{s}$, and the step was $0.2 \mathrm{~m} / \mathrm{s}$. The wind direction angle was $\beta=0 \mathrm{o}, \beta=15 \mathrm{o}$ and $\beta=30$ o respectively. Such angles could be formed by rotating the rotary plate under model.

Conclusion can be draw after uniform flow field wind tunnel test. It is shown that either in the completion state or at the typical construction stage, the wind speed was larger than corresponding flutter checking wind speed, there was no flutter instability occurred. At the same time, there was no obvious vortex-induced vibration occurred under the designed wind speed.

The buffeting displacement responses were obtained by turbulent flow field wind tunnel test for the aero elastic model. The values of buffeting displacement responses under design wind speed for 3 stages and 3 incoming flow direction angles $\left(0^{\circ}, 15^{\circ}\right.$ and $\left.30^{\circ}\right)$ were listed in Table 3 . In Table 3 , $\mathrm{H}, \mathrm{V}, \mathrm{T}$ are buffeting displacement in the direction of horizontal, vertical and torsion about axial of bridge respectively.

It is shown from Table 3. In the completion state of the bridge, under the design wind speed, the lateral and vertical buffeting responses are the maximum when the incoming wind direction is $30^{\circ}$. the torsion responses is the maximum when the incoming wind direction is $0^{\circ}$.

At construction phase of the longest single cantilever, under the design wind speed, the lateral bridge direction and torsion buffeting responses are the maximum when the incoming flow wind direction is $30^{\circ}$. and when the incoming wind direction is $0^{\circ}$, the vertical buffeting responses is the maximum. At construction phase of the longest double-cantilever, under the design wind speed, 
when the incoming wind direction is $0^{\circ}$, the lateral, vertical and torsion buffeting responses are the maximum.

Tab.3 Buffeting Response in Various States

\begin{tabular}{c|c|c|c|c|c|c|c|c|c}
\hline \multirow{2}{*}{$\begin{array}{c}\text { Wind } \\
\text { angle }\end{array}$} & \multicolumn{3}{|c|}{ The finished stage } & \multicolumn{3}{c|}{$\begin{array}{c}\text { The longest double - } \\
\text { cantilever }\end{array}$} & \multicolumn{3}{c}{$\begin{array}{c}\text { The longest single - } \\
\text { cantilever }\end{array}$} \\
\cline { 2 - 10 } & $\begin{array}{c}\mathrm{H} \\
(\mathrm{mm})\end{array}$ & $\begin{array}{c}\mathrm{V} \\
(\mathrm{mm})\end{array}$ & $\begin{array}{c}\mathrm{T} \\
\left({ }^{\circ}\right)\end{array}$ & $\begin{array}{c}\mathrm{H} \\
(\mathrm{mm})\end{array}$ & $\begin{array}{c}\mathrm{V} \\
(\mathrm{mm})\end{array}$ & $\begin{array}{c}\mathrm{T} \\
\left(^{\circ}\right)\end{array}$ & $\begin{array}{c}\mathrm{H} \\
(\mathrm{mm})\end{array}$ & $\begin{array}{c}\mathrm{V} \\
(\mathrm{mm})\end{array}$ & $\begin{array}{c}\mathrm{T} \\
\left({ }^{\circ}\right)\end{array}$ \\
\hline $0^{\circ}$ & 24.3 & 29.5 & 0.093 & 37.1 & 26.6 & 0.091 & 16.9 & 54.1 & 0.056 \\
\hline $15^{\circ}$ & 23.5 & 27.9 & 0.093 & 35.5 & 23.6 & 0.100 & 13.5 & 52.5 & 0.046 \\
\hline $30^{\circ}$ & 29.1 & 34.8 & 0.080 & 40.8 & 24.7 & 0.095 & 14.3 & 55.9 & 0.043 \\
\hline
\end{tabular}

\section{Summary}

The wind tunnel tests and analysis for wind induced performance of Gongan Changjiang combined highway and railway bridge were carried out. Either in the completion state or at the construction stage, flutter critical wind speeds of the girders were greater than the corresponding flutter checking wind speeds, which showed that flutter stability of the bridge sufficiently meet the safety requirements. In the completion state and at the construction stage of the bridge, vortex-induced vibrations were founded under small damping, but amplitudes were small, and may not give rise to bridge damage or uncomfortable driving. The aerodynamic performances of the bridge were good and meet the requirements of the relevant specification.

\section{Acknowledgement}

This research was financially supported by the National Science Foundation of China(Grant NO. 51378443) and the Technology Research and Development Program of China Railway Corporation ( Grant no. 2013G001-B).

\section{References}

[1]General Code for Design of Highway Bridges and Culverts (JTG D60-2004) [S] . BeiJing,China Communications Press, 2004.

[2]Ministry of Transport of the People's Republic of China. Wind-resistent Design Specification for Highway Bridges (JTG/T D60-01-2004) [S]. BeiJing,China Communications Press, 2004.

[3]Zheng Shi-xiong, Li Yong-le,Tao Qi, Wind Tunnel Test on the Aerodynamic Parameters of Tianxingzhou Highway-Railway Bridge Across Yangtze River[J],China Railway Science, VOL.28(92), NO. 2, 2007; P25-31.

[4]G. L. Larose, Experimental Determination of the Aerodynamic Admittance of a Bridge Deck Segment[J], Journal of Fluids and Structures, 1999, V13, No.7: 1029-1040.

[5]Harold R. Bosch, Aerodynamic stability of a truss-stiffened cable-stayed bridge.Journal of Wind Engineering and Industrial Aerodynamics, Volume 36, Part 2, 1990, Pages 1331-1340.

[6]L. Caracoglia, N.P. Jones, Time domain vs. frequency domain characterization of aeroelastic forces for bridge deck sections, Journal of Wind Engineering and Industrial Aerodynamics, 91 (2003) $371-402$.

[7]Hua Yang, Changyong Liu, Ying Sun, et al, Wind suction effect on long-span stiffened steel truss bridges during erection, Journal of Constructional Steel Research, 71 (2012).P38-51. 